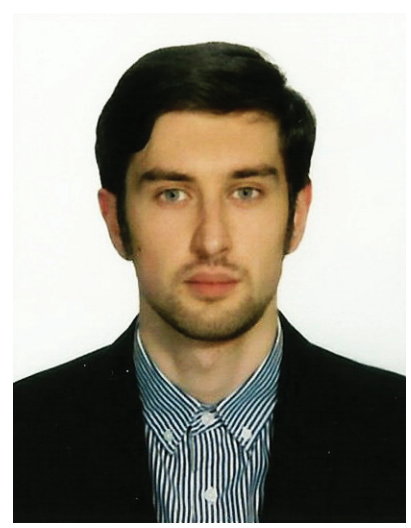

Temuras Jakubovas - Ukrainos nacionalinès

P. I. Čaikovskio muzikos akademijos Ukrainos muzikos istorijos ir muzikinès folkloristikos katedros doktorantas (Ukraina)

Moksliniai interesai: kompozitoriaus Serhijaus

Bortkievičiaus kūryba, muzika smuikui

Tel. + 380935208609

El.paštas: temurdzhon@gmail.com

Temur Yakubov: Post graduate at the History of Ukrainian Music and Musical Folklore-studies department of Tchaikovsky National Music Academy of Ukraine (Ukraine)

Research interests: music by Sergei Bortkiewicz, violin music

Phone: + 380935208609

E-mail: temurdzhon@gmail.com

\title{
Темур Якубов
}

Национальная музькальная академия Украинь имени П. И. Чайковского

\section{СОНАТА ДЛЯ СКРИПКИИ ФОРТЕПИАНО ОР. 26 СЕРГЕЯ БОРТКЕВИЧА : АВТОРСКАЯ ТРАКТОВКА ЖАНРОВОГО ИНВАРИАНТА}

\section{Anotacija}

Šioje publikacijoje tyrinejjama Serhijaus Bortkievičiaus sonata pianinui ir violončelei op. 26 sonatos forma, struktūra bei funkciniai ypatumai. Straipsnyje patikslinama nagrinejjamo darbo sukūrimo data. Publikacijoje taip pat pateikiama istorinė apžvalga, kurioje matyti, kaip susiformavo sonatos žanro invariantas. Galiausiai išsami S. Bortkevičiaus kūrinio analizė leidžia nustatyti Vakarų Europos bei Rusijos kompozicinių tradicijų autoriui padarytą įtaką. Pagrečiui pateikiamos skirtingos kompozicijos interpretacijos (kūrinio aiškinimo metodai), leidžiantys suvokti specifinę ciklo konstrukciją.

PAGRINDINIAI ŽODŽIAI: sonata smuikui, sonatos ciklas, žanro invarianto interpretacija, Serhijaus Bortkievičiaus kūryba.

\footnotetext{
Abstract

The article deals with Sergei Bortkiewicz form, structure and functional experiments on sonata cycle in Sonata for Violin and Piano op. 26. The date of creation of the work is clarified. The article provides an overview of the history of development of the sonata cycle genre invariant. Comprehensive analysis of the work by Bortkiewicz provides tracing influences of West-European and Russian composing traditions. Different approaches to the interpretation of the composer's idea are presented, which allows to explain the specific construction of the cycle.

KEY WORDS: violin sonata, sonata cycle, interpretation of the genre invariant, music by Sergei Bortkiewicz.
} 
Одной из важнейших тенденцией в музыке конца XIX - I пол. XX вв. является стремление к переосмыслению жанрового канона сонатного цикла с использованием приемов, апробированных на протяжении XVIII - XIX вв. Интересным образцом авторского прочтения композиции сонатного цикла выступает соната для скрипки и фортепиано ор. 26 Сергея Борткевича (1877-1952). Произведение является редким для истории украинской музыки образцом романтической скрипичной сонаты. Актуальность работы подчеркивается возрастающим интересом к творчеству композитора: с начала нового столетия о нем были написаны и опубликованы диссертации, научные и научно-популярные статьи в Австрии, Болгарии, Нидерландах, Украине, России, Польше, США, Южно-Африканской Республике и Японии, а в Италии была издана первая монография о С. Борткевиче - "Il confine dell'Inganno" (автор - А. Сольдано). Тем не менее, несмотря на то, что в прощальной речи при погребении композитора в 1952 г. Соната для скрипки и фортепиано была названа лучшим его сочинением (AnkwiczKleehoven 2007, 74), до недавнего времени она оставалась практически неисследованной ${ }^{1}$.

Рукопись скрипичной сонаты С. Борткевича была уничтожена во время Второй мировой войны (Bortkiewicz 2007a), а сведений об истории ее создания практически не сохранилось. Можно предположить, что импульсом к сочинению, как и в случае с концертом С. Борткевича для скрипки с оркестром ор. 22, послужило творческое сотрудничество со скрипачом Ф. Смитом (Bortkiewicz 2007b, 25). Соната была опубликована в издательстве D. Rahter в 1924 г. и большинство исследователей датируют произведение именно этим периодом. Однако, новые сведения из онлайн-архивов исторической периодики позволяют опровергнуть этот взгляд. Удалось установить, что произведение как минимум трижды исполнялось уже в 1923 г. по рукописи - 22 января в Вене (Neues Wiener Journal 1923, 22) и 3 февраля в Гааге (Het Vaderland 1923, 3) Ф. Смитом и С. Борткевичем, а также 6 декабря С. Пикштайнером и П. де Конном в Вене (Neues Wiener Tagblatt 1923, 15). Следовательно, можно утверждать, что соната была завершена в 1922 г., а возможно, (учитывая масштабы цикла и его структурную проработанность, а также период творческого кризиса, связанного с эмиграцией (1920-1921), еще ранее - во время пребывания композитора в Харькове и Ялте (1914-1919).

Анализ композиционного решения сонаты позволяет продемонстрировать значительное переосмысление автором исторически сложившегося

1 Исключение - статья Р. Фельдман «Музыковедческие заметки о С. Борткевиче» (Feldmann 1971, 173). 
жанрового инварианта. Формирование законченного сонатносимфонического цикла относится к этапу зрелого и позднего Классицизма (кон. XVIII - нач. XIX вв.), а жанровые каноны были продиктованы музыкальной эстетикой того времени. Музыковед Н. Горюхина отмечает: «Именно классицизм закрепляет за частями, разделами, партиями сонатной формы ясный функционализм» (Горюхина 1973, 105). В результате формируются две основных 2 разновидности сонаты:

- ориентированная на модель сольного концерта (три части с подвижными крайними и медленной средней);

- ориентированная на симфонический цикл (четырёхчастная: между медленной и финалом присутствует дополнительная часть - менуэт, или, позже, скерцо).

В обоих случаях общая драматургия цикла определяется I частью, написанной почти всегда в сонатной форме. Тональная сфера экспозиции чётко определена: Главная партия (ГП) в основной тональности, побочная (ПП) - тональность V или III ступени. В репризе закрепляется доминирование основной тональности путём транспонирования ПП в основную или одноименную. В ходе эволюции жанрового инварианта тональный контраст постепенно отходит на второй план. Если на раннем этапе становления он зачастую оказывался решающим (вплоть до использования для ГП и ПП одной темы, но в разных тональностях), а в период зрелого Классицизма тональный и тематический контрасты примерно равнозначны, то в послебетховенскую эпоху на первом плане оказываются образно-тематические конфликты, в то время как тональные соотношения индивидуализируются (Мазель 1979, 364).

Медленная вторая часть цикла привносит новый тональный контраст: часто тональность субдоминанты $(\mathrm{S})$, значительно реже одноименная или доминантовая (D) (Кюрегян 1998, 130). Финал возвращает в основную тональность или одноименный мажор. Наиболее распространённая форма - рондо. Типичная метрическая драматургия цикла - 4/4 в первой части, $3 / 4$ во второй и 6/8 (слияние двух- и трёхдольности) в финале.

Благодаря выходу на философский, онтологический уровень осмысления Человека (Арановский 1979, 24) сонатно-симфонический цикл надолго занимает доминирующее место в творчестве композиторов классико-романтической эпохи. А соната ещё и выступает в роли «ворческой лаборатории» в поиске новых композиционных решений.

2 Т. Кюрегян относит к нормативу также двухчастный цикл с пропущенной или интегрированной в финал медленной частью и пятичастный цикл (Кюрегян 1998, 129). 
В поздних произведениях Л. Бетховена, в творчестве последующих поколений композиторов наблюдаются тенденции к более свободному выбору тонального плана, увеличению масштабов, изменению последовательности частей цикла. С другой стороны, у композиторов-романтиков появляются образцы сжатия цикла в одночастное произведение. В сонату привносится монологическая концепция жанра с соответствующим комплексом приёмов и методов развития музыкального материала (монотематизм, лейттематизм). Появляются образцы трех-, а иногда и четырехтональной экспозиции, субдоминантовой репризы. Основной конфликт может смещаться с пары ГП/ПП на вступление/экспозицию, экспозицию/разработку. Главный драматический перелом иногда оказывается в зоне заключительной партии (3П) (Холопова 1999, 338).

Скрипичная соната С. Борткевича соответствует более ранней, классической модели жанра (ориентированной на концерт) и содержит три части традиционного типа: «быстро - медленно - быстро». Однако, при сохранении внешних признаков классического канона, более глубокий анализ позволяет проявить ряд инноваций, связанных с эстетикой романтизма и нач. XX в.

Первая часть в сонатной форме в характере Allegro dramatico, вторая медленное лирическое Andante в трёхчастной форме. Третья часть - традиционное для финала Allegro vivace e con brio. Ладотональная драматургия корреспондирует с бетховенской модуляцией в цикле: отклонение в субдоминантовую тональность во II части и переход в одноименный мажор в финале.

Отход от традиции отмечается в метрическом решении сонаты - все три части написаны в четырёхдольном метре, что указывает на индивидуальный подход в формировании образной системы и концепции цикла. Отдельно отметим присутствие в скрипичной сонате С. Борткевича тем, которые позиционируются композитором как исходный интонационно-образный комплекс для построения остального тематического материала. Сквозное использование ряда тем на протяжении всего цикла как в их первозданном виде, так и в виде вычленения отдельных характерных мотивов, служащих материалом для новых тематических образований, закладывает основу тематического развития и создаёт целостность драматургии сонаты.

Уже в начале первой части С. Борткевич размещает медленный вступительный раздел Sostenuto, где экспонирует две темы. Метод их использования и роль их в формировании тематизма сонаты можно определить как монотематический, ведь обе темы, и как законченные тематично-образные построения, и в виде отдельных мотивов, принимающих на себя фун- 
кцию образной доминанты новых тем, способствуют моноинтонационному принципу в реализации интонационно-образной системы сонаты. Такой подход характерен именно для романтического сонатно-симфонического цикла (Симфония №8 Ф. Шуберта, Симфония а-moll Ф. Мендельсона, Соната h-moll Ф. Листа).

Первая, наиболее значимая тема dolce экспонируется у $\phi-$ но в основной тональности g-moll с преобладающим топосом чувствительности, скорби, меланхолии (Кириллина 2007, 50, 88). Показательно метрическое решение темы: устойчивый, уравновешенный размер 4/4, который, однако же, расшатывается как на уровне ритмики (отсутствие первой сильной доли эффект долгого затакта), так и структуры (мелодика - дробление мотива; композиция - неквадратный период 3+3). Интонационно мотив сильно хроматизирован с доминированием нисходящих интонаций (родственность риторической фигуре passus duriusculus). Пунктирный ритм в кульминационных зонах подчеркивает комплекс семантических кодов трагической образности. Строго четырёхголосная фактура привносит жанровый подтекст хорала. Проведению темы dolce у $\phi$-но отвечает монолог скрипки. Речитатив после хоральной фактуры проявляет авторскую трактовку функции инструментов в сонате - личностное начало у скрипки, внешнее объ-

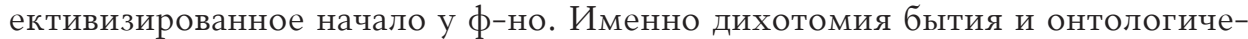
ский конфликт внутреннего и внешнего мира Человека является основным импульсом творчества для романтического мировосприятия. Дальнейший музыкальный материал подтверждает подобную трактовку - в репризном подразделе скрипка перенимает верхний голос хорального мотива. Это можно трактовать как отказ от личностного, либо уступку, попытку найти компромисс, что однако же приводит к появлению трагической второй темы вступления dolente.

Вторая тема вступления во многом контрастна теме dolce, хоть и сохраняет сдержанный темп, близкую (но не идентичную) образную сферу. Далёкая от основной тональность h-moll (3-я степень родства) характеризует трагико-патетический (вместо скорбно-меланхолического) круг образов (Сонаты h-moll Ф. Листа и Ф. Шопена, Симфония №6 П. Чаковского). Несмотря на сохранение четырёхголосной фактуры, чётко выделяется солирующий верхний и сопровождающие голоса. Метрика, в отличие от первой темы, подчёркнуто равномерна и непоколебима, каждый такт - завершённый и уравновешенный мотив. Основная ритмоинтонация темы dolente «мотив судьбы»³, за которым ещё в творчестве венских классиков утвер-

3 Название, введённое в обиход биографом Л. Бетховена А. Шиндлером и закрепившееся в музыковедческих кругах (Кириллина 2007, 38). 
дилось значение риторического вопроса (Кириллина 2007, 38). Сильная доля подчёркнута глубоким басом (ре контроктавы), что формирует образ колокольности (См.: Хадеева 2004). Дополнительное родство с русской музыкальной традицией создаётся гармонизацией: использованием «рахманиновского аккорда» - энгармонически равного вводному септаккорду с квартой. Остинатность материала, пунктирный ритм в кульминационных зонах такта подчеркивает трагический топос, привносит жанровый подтекст похоронного шествия. Однако при попытке проведения темы в третий раз мерная поступь фортепианного аккомпанемента прерывается, возвращаются вопросительные интонации в монологическом изложении скрипки. Личность не вписывается в общую картину, ставит её под сомнение.

В современном музыковедении можно выделить несколько подходов к анализу формы, среди которых: структурный (механистическое разделение целостного произведения на составляющие структурные элементы формы) и функциональный (согласно Е. Назайкинскому: «такой подход, при котором те или иные явления музыки, ее единицы, входящие в целостный комплекс, рассматриваются с точки зрения роли, которую они в нем выполняют. Последняя и обозначается словом «функция» (Назайкинский 1982, 54)).

И если с точки зрения структуры форма I ч. сонаты не вызывает особых вопросов, то функции вычлененных разделов гораздо более специфичны, отличны от общепринятого жанрового инварианта. Вступление в сложной двухчастной форме имеет все признаки экспозиции сонатной формы: две конфликтные темы с тональным контрастом (g-moll/h-moll - параллель к мажорной доминанте D-dur), каждая со своим экспозиционным развитием уже во вступлении и дальнейшей разработкой на протяжении всего сонатного цикла.

Более того, ГП сонатного аллегро, врывающаяся после вступительного раздела, уже несёт в себе черты разработочности: тема построена на столкновении элементов двух мотивов вступления (хроматическое опевание из темы dolce у скрипки и ритмоформулу «мотива судьбы» из темы dolente у ф-но). ПП формируется из тематического материала первой темы вступления (хроматический спуск, мотив из кульминационной зоны - восходящий пунктир с возвратом на следующую долю). Тональность неустойчива, что опять же привносит элемент разработочности. На кульминации ПП врывается I тема вступления в характере violente. 3П тоже построена на тематическом материале вступления (пунктирный мотив у скрипки и нисходящий хроматический ход с использованием ритмоформулы «мотива судьбы» у ф-но). 
Короткий разработочный раздел сопоставляет тематизм ГП и ЗП. Реприза динамизирована при помощи насыщения фактуры, изменения динамики. Увеличен объем за счет дополнительного тонального развития темы ГП. Основная тональность g-moll избегается. В итоге опять же создаётся эффект разработочности излагаемого материала. Заключительный тип изложения музыкального текста (в том числе и закрепление основной тональности g-moll) появляется лишь в двух эпизодах развёрнутой коды.

В итоге, основные по классическому канону разделы формы у С. Борткевича частично уступают свои функции в пользу структур, ранее позиционировавшихся как вспомогательные. С одной стороны, есть разработка материала экспозиции сонатного аллегро и вывод его на новый уровень содержания в репризе. С другой, сама экспозиция, наряду с разработкой и репризой лишь развивает конфликт, ранее показанный во вступительном разделе, а частичное разрешение конфликта присутствует лишь в коде, несущей таким образом функцию репризы.

Bo второй части, Andante, в тональности с-moll доминирует трагико-патетическая образная сфера. Небольшое по размерам вступление содержит, тем не менее, мотив, который станет репрезентантом трагической образной сферы в финале. Основной раздел написан в традиционной для II ч. цикла трёхчастной репризной форме. Однако средний подраздел, вместо контрастного или разработочного эпизода, содержит трёхчастную безрепризную форму низшего порядка со своим экспозиционным и разработочным эпизодами, трагической кульминацией всего сонатного цикла и скрипичной каденцией. Показательно, что развёрнутая кода второй части тематически оторвана от предшествующего материала и является усечённым вариантом вступления к I ч. Аналогия вступительного раздела I ч. с экспозицией инварианта сонатного аллегро тем очевиднее, что кода II ч., содержащая тот же материал, но в общей тональности (c-moll) напоминает репризу некоего общего построения I-II чч. сонаты, которые к тому же по образному наполнению (трагико-драматические) противопоставлены радостному финалу, образуя субцикл, объединённый арочным приёмом.

Финал сонаты в тональности G-dur образно противопоставлен драматической первой и трагической второй частям. Структура III ч. неоднозначна и позволяет говорить о сонатном аллегро с элементами рондальности. Характерные мотивы народных наигрышей, арпеджиато $\phi-$ но, pizz. скрипки формируют топос пасторали, образную сферу народных гуляний. Связующая партия (СП) на материале главной темы финала расположена между двумя темами ПП, а не между ГП и ПП. Комплекс ГП, СП и ЗП основанный на едином тематизме и чередующийся с двумя темами ПП формиру- 
ет элемент рондальности. Экспозиция, как и в первой части, прерывается I темой вступления из I ч. В разработке используется чуждый для финала материал - темы вступления I ч., вступления II ч., а также мотив B-A-C-H, привносящий свой, укрепившийся в музыке к нач. XX в., образно-семантический комплекс (См.: Robinson 1973). Чуждый тематизм поочерёдно отметается и в репризе возвращается доминирующая образная сфера финала. Тем не менее, с тональной точки зрения реприза не просто не возвращается в основную, но уводит музыку в еще более далекие тональности доминантовой сферы, что опять же привносит элемент разработочности. Появившаяся было вновь тема вступления к I ч. прерывается объёмной насыщенной кодой на материале 3П, ГП и ПП финала. Тема ПП в коде переосмысливается на лирический манер и в конце концов уступает место доминирующей ГП.

Целостность столь насыщенной структуры трёхчастного цикла обеспечивается тематическими арками, которые связывают все части в единую смысловую формацию. Таким образом соната для скрипки и фортепиано ор. 26 Сергея Борткевича по своей архитектонике является сложной многоуровневой структурой (как бы, напоминает матрёшку): целостный трёхчастный цикл делится на трагико-драматический субцикл (I и II чч.) и жизнеутверждающий финал; субцикл в свою очередь состоит из двух частей, первая из которых содержит композиционное формирование высшего порядка «вступление - сонатное аллегро - кода», внутри которого сонатное аллегро имеет классическую структуру из экспозиции, разработки и репризы. Вторая часть, в свою очередь, содержит три раздела с изолированным тематизмом (вступление - основная часть - кода), основная часть - типичная трёхчастная репризная структура, средний подраздел в которой содержит трёхчастное безрепризное образование низшего порядка с центральным разработочным эпизодом и кульминацией. Кроме того, соната проявляет тяготение С. Борткевича к пересмотру и, частично, отказу от классического репризного построения, сама идея которого не всегда соответствует художественным установкам композитора. У С. Борткевича развитие музыкального материала в разработочных разделах приводит к полному его переосмыслению (реприза I ч. и финала), а иногда и к отказу от изначального тезиса (безрепризные трёхчастные построения со средним разделом разработочного характера - «форма высшего порядка» I ч., средний раздел II ч., внутреннее строение разработки финала). Соответственным образом возрастает значимость тех структурных образований, которые проводятся после такой «переосмысленной репризы» (собственно репризный раздел во II ч., кода I и III чч.). Описанная сложная многоуровневая организация музыкального текста обеспечивает архитектоническую устойчивость и сба- 
лансированность сонаты, насыщенной общим тематизмом, логика расположения которого подчиняется не только (и не столько) структурному, но и идейно-содержательному замыслу композитора.

Интерпретация художественного замысла сонаты для скрипки и фортепиано С. Борткевича может быть представлена несколькими вариантами. Один из них некоторым образом корреспондирует с замыслом, например, увертюры «Эгмонт» Л. Бетховена (Кириллина 1999, 136): медленное вступление (гнет испанских завоевателей), активное сонатное аллегро (борьба главного героя за свободу родины), трагическая развязка (смерть героя) и триумфальная мажорная кода (неотвратимое торжество идеалов, за которые умер герой). Естественно, семантическая концепция традиционной трёхчастной сонаты не может быть настолько персонифицированной, как программная увертюра. Более того, герой-«титан», характерный для творчества Л. Бетховена, отнюдь не соответствует более человечному, сосредоточенному на ценностях субъективного внутреннего мира романтическому герою. Тем не менее, чётко прослеживается аналогия: медленное вступление, в котором заложен конфликт между героем и враждебным ему внешним миром, драматическое сонатное аллегро первой части (борьба), трагическая вторая часть с кодой, оканчивающейся похоронным шествием (смерть, или, как минимум, поражение героя), радостный финал, в котором демонстрируется фиаско фатальной образной сферы путём замещения трагико-драматических интонационно-образных комплексов субцикла, представленных в разработке III ч., светлым основным тематизмом финала в коде. Пасторально-народный характер музыки III ч. позволяет провести аналогии с общими идеями народничества: возвращение «цивилизованного» человека с его неразрешимыми конфликтами «в народ», который идеализируется, или попытка найти утешение в жизни простых людей с её незатейливыми радостями, жить «чужим счастьем» (как в финале Симфонии №4 П. Чайковского (Чайковский 1934, 216-219)).

Другим вариантом выступает автобиографическая концепция сонаты. События 1914-1920 гг. трагически отобразились в судьбе С. Борткевича: сначала его депортировали из Берлина из-за событий Первой мировой войны, затем он пережил репрессии со стороны режима большевиков, а в 1920 г. композитор навсегда оставил родину. Жизнь эмигранта в Стамбуле была невероятно сложной. И лишь в 1922 г. С. Борткевич оказался в Австрии, где перед ним открылись новые горизонты для творческой реализации.

Композиция скрипичной сонаты, сочинявшейся в Харьковский период и завершённой в первые годы проживания в Вене имеет определённые ана- 
логии с описанным периодом жизни композитора. В произведении можно найти и несколько меланхолическую тоску о довоенном Берлине (и вообще о лучшей довоенной жизни), и отображение драматических событий войны и революции, и весь трагизм человека, вынужденного навсегда покинуть родную землю (образная сфера субцикла I и II чч.). Финал может отображать оптимистический взгляд в будущее композитора, попавшего в одну из мировых музыкальных столиц (перед которым, соответственно, открылись огромные перспективы для творческой деятельности), либо быть воспоминанием, например, о Пасхальных торжествах в Харькове, описываемых С. Борткевичем в своих «Воспоминаниях» (Bortkiewicz 2007b, 8). В любом случае, многоуровневость содержания произведения, интересная своеобразная форма цикла и широкие возможности его разнообразной интерпретации характеризуют сонату для скрипки и фортепиано ор. 26 Сергея Борткевича, как сочинение, достойное внимания исследователей-музыковедов и музыкантов-исполнителей, как яркий образец скрипичной сонаты І пол. XX века.

\section{Литература}

Ankwicz-Kleehoven 2007 - Hans Ankwicz-Kleehoven. At the grave of Serge Bortkiewicz (4 November 1952). In Recollections, letters and documents of Sergei Bortkiewicz translated from German and annotated by B. Thadani. $3^{\text {rd }}$ ed. Winnipeg, Canada: Cantext Publications, 73-74.

Bortkiewicz 2007a - Sergei Bortkiewicz. Letter to Hugo van Dalen from 29 May 1944. In Recollections, letters and documents of Sergei Bortkiewicz translated from German and annotated by B. Thadani. $3^{\text {rd }}$ ed. Winnipeg, Canada: Cantext Publications, P. 62.

Bortkiewicz 2007b - Sergei Bortkiewicz. Recollections. In Recollections, letters and documents of Sergei Bortkiewicz translated from German and annotated by B. Thadani. $3^{\text {rd }}$ ed. Winnipeg, Canada: Cantext Publications, 1-35.

Feldmann 1971 - Ria Feldmann. Musikwissenschaftliche Anmerkungen zu Sergei Bortkiewicz. In Musik des Ostens. Kassel, Deutschland: Bärenreiter Verlag, Band 6, 170-184.

Het Vaderland 1923 - Newpaper. 4 February. Available at: https://www.delpher.nl/nl/kranten/vi ew?coll $=$ ddd \& cq $1 \% 5 \mathrm{~B} \% 5 \mathrm{D}=\% 28$ date $\% 3 \mathrm{D} \% 2204-02-1923 \% 22 \% 29 \&$ facets $\% 5$ BtitleString $\% 5$ $\mathrm{D} \% 5 \mathrm{~B} \% 5 \mathrm{D}=$ Het + Vaderland $+\% 3 \mathrm{~A}+$ staat $-+\mathrm{en}+$ letterkundig + nieuwsblad\& resultscoll= dddtitel \&identifier $=\mathrm{ddd} \% 3 \mathrm{~A} 010008289 \% 3 \mathrm{Ampeg} 21 \% 3 \mathrm{Ap} 003$ (accessed: 21.01 .2019 ).

Neues Wiener Journal 1923 - Newspaper. 14 January. Available at: http://anno.onb.ac.at/cgicontent/anno?aid $=$ nwi\&datum $=19230114 \&$ zoom $=33$ (accessed 02.02.2019)

Neues Wiener Tagblatt 1923 - Newspaper. Tages-Ausgabe, Nr.323. 25 November. Available at: http://anno.onb.ac.at/cgi-content/anno?aid $=$ nwg \& datum $=19231125 \&$ zoom $=33 \quad$ (accessed 02.02.2019)

Robinson 1973 - Schuyler Watrous Robinson. The B-A-C-H motive in German keyboard compositions from the time of J.S. Bach to the present. Ann Arbor, Michigan : Univ. Microfilms, $136 \mathrm{p}$.

Арановский 1979 - Марк Генрихович Арановский. Симфонические искания. Ленинград: Советский композитор, 288 с.

Горюхина 1973 - Надежда Александровна Горюхина. Эволюция сонатной формыл. Изд. 2-е, дополненное. Киев: Музична Україна, 311 с. 
Кириллина 1999 - Лариса Валентиновна Кириллина. Эгмонт. Гётевские чтения 1999. Москва: Наука, 136-150.

Кириллина 2007 - Лариса Валентиновна Кириллина. Классический стиль в музыке XVIII начала ХІХ века. Часть III: Поэтика и стилистика. Москва: Композитор, 367 с.

Кюрегян 1998 - Татьяна Суреновна Кюрегян. Форма в музыке XVII - XX веков. Москва: Сфера, 344 c.

Мазель 1979 - Лев Абрамович Мазель. Строение музыкальныхх произведений. Москва: Музыка, 536 с.

Назайкинский 1982 - Евгений Владимирович Назайкинский. Логика музыкальной композиции. Москва: Музыка, 319 с.

Хадеева 2004 - Елена Николаевна Хадеева. Колокольная образность в русском музыккальном искусстве XIX - начала XX века: автореф. дис. ... канд. искусствоведения: 17.00.02 «Музыкальное искусство». Казанская гос. консерватория им. Н. Г. Жиганова. Казань, 24 с.

Холопова 1999 - Валентина Николаевна Холопова. Формы музыкальных произведений. Санкт-Петербург: Лань, 496 с.

Чайковский 1934 - Петр Ильич Чайковский. Переписка с Н. Ф. фон-Мекк: в 3 т. МоскваЛенинград: ACADEMIA, T. 1 (1876-1878), 644 с.

\section{Temur Yakubov}

SONATA FOR VIOLIN AND PIANO OP. 26

BY SERGEI BORTKIEWICZ: AUTHOR'S

\section{INTERPRETATION OF A GENRE INVARIANT}

Summary

Despite growing interest in music of Sergei Bortkiewicz all over the world, his Sonata for Violin and Piano op. 26 has not yet become an object of comprehensive research and analysis. The original manuscript was burnt during the Second World War, and information about the history of its creation was almost not preserved. It can be assumed that the impulse to the composition was a creative collaboration with violinist Frank Smith. The sonata was published by the D. Rahter publishing house in 1924. However, new information from online archives of historical periodicals (a fact of performance in January 1923) proves that it was composed in 1922 or even earlier.

The analysis of the compositional solution of the sonata allows to demonstrate a significant rethinking by the author of the historically established genre invariant. The form, used by Bortkiewicz, corresponds to an earlier, classical model of the genre (concerto-oriented) and contains three parts of the traditional type: “quickly - slowly - quickly”. Key dramaturgy reminds Beethoven’s modulation in the cycle: subdominant tonality in second movement and parallel major in final movement. Bortkiewicz used a few themes throughout the cycle, either in their original form or as motifs for new thematic formations, which ensures the integrity of the form. In addition, Violin Sonata is showing Bortkiewicz to revise 
and partly to abandon the classical recapitulative construction, the very idea of which does not always correspond to the composer's idea.

The work in its architectonics is a complex multi-level structure. Identical themes for 1st mvt preamble and 2nd mvt coda formed the arch which separates "subcycle" of 1-2 movements from finale mvt. Preamble of the 1st mvt introducing two themes in different character can be interpreted as an exposition of allegro sonata form. At the same time, allegro sonata of the 1st mvt itself reminds a development of the preamble.

The idea of the Violin Sonata by Bortkiewicz can be interpreted in several ways. One corresponds to Beethoven's "Egmont" overture. The slow preamble establish conflict between the hero and the hostile external world. The dramatic sonata allegro of the first part shows the struggle, tragic second part with funeral procession in the code illustrate death, or at least the defeat of the hero. In the 3rd mvt tragic and dramatic themes of subcycle, used in development episode, in recapitulation are replaced with main thematic complex of the joyful finale. Pastoral style of the finale corresponds to Tchaikovsky. Another version is biographical: 1st mvt could illustrate deportation from Germany, war and repressions of the red regime in Kharkiv, 2nd depicts the grief of emigration, 3rd is either inspiration with new life in Austria or reminiscence of Easter celebration described in composer's Recollections. 